\title{
Corrigendum \\ Loss of Environmental Enrichment Increases Vulnerability to Cocaine Addiction
}

Joelle Nader, Chauvet Claudia, Rana El Rawas, Laure Favot, Mohamed Jaber, Nathalie Thiriet and Marcello Solinas

Neuropsychopharmacology (2014) 39, 780; doi:10.1038/npp.2013.303

Correction to: Neuropsychopharmacology (2012) 37, In this article, the images labeled SE-EE and EE-EE in 1579-1587; doi:10.1038/npp.2012.2; published online $15 \quad$ Figure $6 \mathrm{~b}$ are duplicates. The correct images are provided February 2012 below.

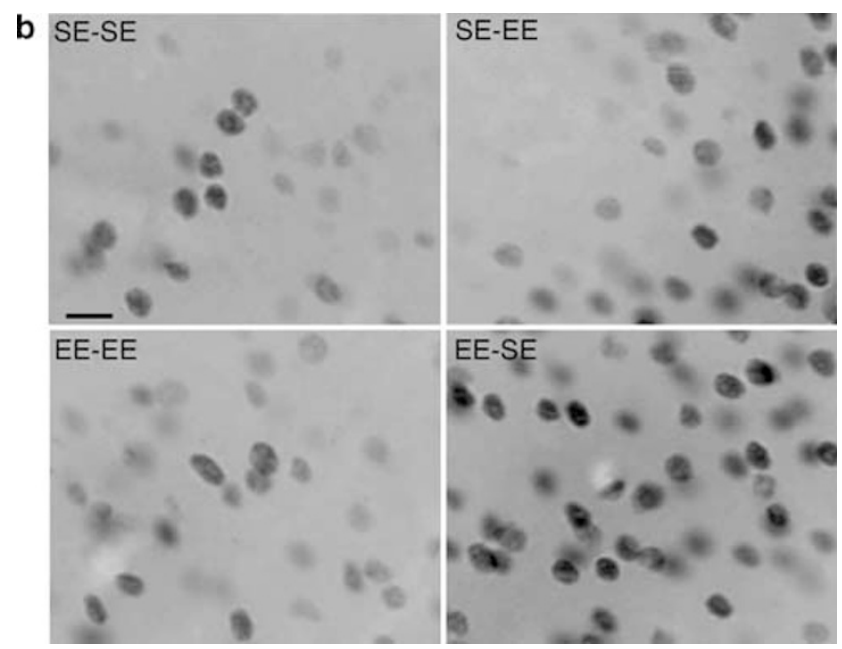

